Review

\title{
Cannabis: From a Plant That Modulates Feeding Behaviors toward Developing Selective Inhibitors of the Peripheral Endocannabinoid System for the Treatment of Obesity and Metabolic Syndrome
}

\author{
Shira Hirsch and Joseph Tam *(1) \\ Obesity and Metabolism Laboratory, Institute for Drug Research, School of Pharmacy, Faculty of Medicine, \\ The Hebrew University of Jerusalem, Jerusalem 9112001, Israel; shirah@ekmd.huji.ac.il \\ * Correspondence: yossit@ekmd.huji.ac.il; Tel.: +972-2-675-7645
}

Received: 24 April 2019; Accepted: 12 May 2019; Published: 15 May 2019

\begin{abstract}
In this review, we discuss the role of the endocannabinoid (eCB) system in regulating energy and metabolic homeostasis. Endocannabinoids, via activating the cannabinoid type-1 receptor $\left(\mathrm{CB}_{1} \mathrm{R}\right)$, are commonly known as mediators of the thrifty phenotype hypothesis due to their activity in the central nervous system, which in turn regulates food intake and underlies the development of metabolic syndrome. Indeed, these findings led to the clinical testing of globally acting $\mathrm{CB}_{1} \mathrm{R}$ blockers for obesity and various metabolic complications. However, their therapeutic potential was halted due to centrally mediated adverse effects. Recent observations that highlighted the key role of the peripheral $\mathrm{eCB}$ system in metabolic regulation led to the preclinical development of various novel compounds that block $\mathrm{CB}_{1} \mathrm{R}$ only in peripheral organs with very limited brain penetration and without causing behavioral side effects. These unique molecules, which effectively ameliorate obesity, type II diabetes, fatty liver, insulin resistance, and chronic kidney disease in several animal models, are likely to be further developed in the clinic and may revive the therapeutic potential of blocking $\mathrm{CB}_{1} \mathrm{R}$ once again.
\end{abstract}

Keywords: Cannabis; marijuana; CB1 receptor; central CB1 receptor blockade; peripheral CB1 receptor blockade

Key Contribution: This paper provides an overview of the regulatory role that cannabinoid-1 receptor $\left(\mathrm{CB}_{1} \mathrm{R}\right)$ plays in feeding behaviors in the central nervous system and metabolism and energy homeostasis in peripheral organs. Emphasis is placed on the preclinical development of novel drugs that block $\mathrm{CB}_{1} \mathrm{R}$ in the periphery to ameliorate obesity, type II diabetes, fatty liver, and chronic kidney disease by counteracting the enhanced 'endocannabinoid tone' found in these metabolic abnormalities.

\section{Overview of Plant Cannabinoids and Endocannabinoids}

Throughout human history, plants have been used as a predominant source of medications. The genus Cannabis includes up to three strains, Cannabis sativa, Cannabis indica, and Cannabis ruderalis, each with a very long history of domestication [1]. These strains can be separated by morphology, by phytochemistry, and by differences in their original geographic area. Hybrid variations of these strains have been developed to strengthen some specific characteristics in order to make cannabis an effective drug [2]. Regarding its unique chemistry, Cannabis sativa (marijuana) is considered one of the most resourceful plants, research investigations of which during the past half-century have led to the discovery of an important homeostatic system, the endocannabinoid (eCB) system, which plays a key role in human physiology (reviewed in [3]). Currently, 545 natural compounds have 
been identified from this plant [4]. Of these, 144 have been isolated and identified as cannabinoids (phytocannabinoids) [5]. The first attempt to successfully identify a cannabinoid was made in 1899 by Wood and colleagues [6], who isolated cannabinol (CBN). However, it took almost forty years and several groups' efforts to identify the correct structure of CBN (reviewed in [7]). Interestingly, the most advanced characterization of different phytocannabinoids was done during the 1960s by Mechoulam's group, who isolated and reported the correct structure and stereochemistry of cannabidiol (CBD) [8], $\Delta^{9}$-tetrahydrocannabinol $\left(\Delta^{9}\right.$-THC, the main psychoactive component of marijuana) $[9,10]$, $\Delta^{8}$-tetrahydrocannabinol ( $\Delta^{8}$-THC) [11], cannabigerol (CBG) [12], cannabichromene (CBC) [13], and cannabicyclol (CBL) [14].

Since then, three decades had passed until the binding sites of $\Delta^{9}$-THC in the brain and peripheral organs were identified, which were then termed as the cannabinoid- 1 and -2 receptors $\left(C_{1} R\right.$ and $\mathrm{CB}_{2} \mathrm{R}$, respectively) [15-17]. As of recently, their structures have been cloned and reported by several groups [18-21]. These characterizations will significantly aid in developing more specific synthetic cannabinoids in the future. Signaling by both receptors is mainly mediated via $G_{i} / G_{0}$ proteins, despite the fact that they can also recruit $G_{s}$ and $G_{q / 11}$ proteins and facilitate $G$ protein-independent molecular pathways [22]. $\mathrm{CB}_{1} \mathrm{R}$, primarily localized in the cell membrane, is the most widely expressed G-protein coupled receptor (GPCR) in the human brain [23], but it is also abundantly expressed in peripheral organs [24]. $\mathrm{CB}_{2} \mathrm{R}$, on the other hand, is predominantly localized in immune cells and is moderately expressed in many peripheral tissues, with conflicting evidence regarding its expression in the central nervous system (CNS) [25]. Of the 144 phytocannabinoids present in Cannabis, only $\Delta^{9}$-THC and its less abundant propyl analogue, $\Delta^{9}$-tetrahydrocannabivarin (THCV), have been shown to bind to $\mathrm{CB}_{1} \mathrm{R}$ and $\mathrm{CB}_{2} \mathrm{R}$ with high affinity (with agonistic and antagonistic activity for $\mathrm{THC}$ and $\mathrm{THCV}$, respectively). Regarding other cannabinoids, studies have shown their ability to bind to several different receptors, ranging from other GPCRs (GPR18, GPR55, and GPR119) to ion channel (thermosensitive transient receptor potential (TRP) channels) and nuclear receptors (peroxisome proliferator-activated receptors, PPARs) (reviewed in [26]); however, their physiological functions are still largely unknown.

The successful cloning and identification of $C_{1} R$ and $C_{2} R$ in mammalian cells prompted the discovery of their first endogenous ligand, arachidonoyl ethanolamide (AEA, or anandamide) [27], which was then followed by identifying 2-arachidonoyl glycerol (2-AG) [28,29]. Whereas AEA is a high-affinity, partial agonist of $C_{1} R$, and barely active at $C_{2} R, 2-A G$ is known to activate both receptors with moderate-to-low affinity [30,31]. Both eCBs are synthesized, transported, and inactivated in their respective target tissues differently. Whereas AEA is catalyzed from $N$-acyl-phosphatidylethanolamine (NAPE) by NAPE-specific phospholipase D (NAPE-PLD) or via other means [3], 2-AG is mainly generated from diacylglycerol (DAG) by either DAG lipase (DAGL) $\alpha$ or $\beta$ [32]. Their degradation depends on the specific cellular uptake and enzymatic catabolism. AEA is degraded primarily by membrane-associated fatty-acid amide hydrolase (FAAH) into free arachidonic acid and ethanolamine [33], whereas 2-AG is predominantly hydrolyzed by monoglyceride lipase (MAGL) into arachidonic acid and glycerol [34].

The eCB system, acting both centrally and peripherally, is an important physiological system, comprising the cannabinoid receptors and their natural endogenous ligands as well as the enzymes/proteins involved in their biosynthesis, transport, and degradation. It is involved in many physiological and pathological conditions and functions as a regulatory homeostatic system in various tissues, such as the brain, skin, liver, cardiovascular system, bone, kidney, pancreas, adipose and muscle tissues, the digestive track, and many more (reviewed in [3]). Since it is ubiquitously present in humans and animals, it has been suggested that its homeostatic roles are "relax, eat, drink, rest, sleep, save, store, forget, and protect" [35]. Therefore, changes in eCB 'tone', represented by the expression of the cannabinoid receptors, their functional activity (upregulated or downregulated), and the relative amount of eCBs, may render the subject susceptible to different diseases. For instance, enhanced $\mathrm{eCB}$ 'tone' has been linked to the development of many metabolic diseases (e.g., obesity, type II diabetes, fatty liver disease, and chronic kidney diseases) [24], whereas reduced eCB 'tone', also 
termed 'clinical eCB deficiency syndrome', is associated with migraine, fibromyalgia, irritable bowel syndrome, schizophrenia, multiple sclerosis, Huntington's, Parkinson's, anorexia, chronic motion sickness, and autism [36-38]. Therefore, utilizing different approaches to achieve modulatory effects on the $\mathrm{eCB}$ system and 'normalize' its action under these conditions (by using various phytocannabinoids, synthetic cannabinoids, and novel drugs that may affect $\mathrm{eCB}$ ligand synthesis or degradation) is advised.

\section{Is Marijuana a Toxic Drug?}

Cultivated for millennia, marijuana still has a remarkable ability to alleviate different physical pathologies. To date, the U.S. Federal Food, Drug, and Cosmetic Act defines marijuana as a drug, taken by either smoking or consuming it orally for therapeutic purposes. As a drug, it may also cause harm and has toxic effects. Thus far, only limited reports related to the side effects of marijuana used for medical purposes have been reported. This contradicts the existing information regarding its recreational use, as well as in comparison to other drugs (e.g., morphine and cocaine). Whereas the latter drugs may cause death when consumed inappropriately, mainly due to respiratory arrest $[39,40]$ and/or increasing the blood pressure and heart rate [41,42], no such evidence has been reported with the use of marijuana. Nevertheless, a few generalized findings are related to the acute and chronic side effects of cannabis use. Among them, cannabinoids have been shown to affect: (i) the cardiovascular system (acute use is associated with tachycardia and increased blood pressure vs. chronic exposure that results in the opposite effects); (ii) the respiratory system, in which inflammation of the lungs and large airways is increased; bronchitis and emphysema have been documented with the chronic use of cannabis; (iii) cognition, by reducing attention, sensory perception, task acquisition, and working memory; and (iv) mental illness and psychiatric conditions, including depression, anxiety, psychosis, bipolar disorder, and schizophrenia (summarized in [43-46]).

\section{3. "To Eat or Not to Eat": The Role of Cannabinoids in Feeding Behaviors}

Although not toxic, a common 'side effect' of cannabis use is an increase in appetite. This well-known property, coupled with the existence of $\mathrm{CB}_{1} \mathrm{R}$ within appetite-related brain areas [47], suggests that the $\mathrm{eCB}$ system plays a key role in regulating feeding and body weight. For centuries, marijuana has been recognized as a food intake stimulant. Although the first evidence of cannabis use for treating appetite loss was reported in 300 A.D. in India, a few studies conducted in humans during the $20^{\text {th }}$ century firmly supported the ability of cannabis consumption to induce hyperphagia and snacking (collectively referred to as 'the munchies'; summarized in [48]). Indeed, marijuana use in healthy normal volunteers has been shown to increase daily caloric intake, which is mainly because of enhanced food intake between meals rather than an increase in meal size [49]. Orally administered $\Delta^{9}$-THC or cannabis smoking enhances the consumption of highly palatable and sweet snack foods and increases the qualitative ratings of hunger [49-51], findings that support the role of the $\mathrm{eCB} / \mathrm{CB}_{1} \mathrm{R}$ system in regulating feeding behaviors via the reward system [52]. These cumulative data actually support the clinical evaluation and testing of cannabinoid therapeutics to stimulate appetite in cancer patients undergoing chemotherapy [53], individuals with HIV/AIDS [54-57], and anorexia nervosa [58] as well as in anorexic Alzheimer's disease patients [59,60].

Accumulating basic evidence also supports the orexogenic effects of cannabinoids, demonstrating increased food intake by administering $\Delta^{9}-$ THC in various animal models [61-65]. However, our current understanding of cannabinoid action on food intake was revolutionized after $C_{1} R$ was identified in various brain regions, including the hypothalamus, which plays a key role in homeostatic regulation. Indeed, direct activation of $\mathrm{CB}_{1} \mathrm{R}$ by $\mathrm{AEA}$ has been shown to stimulate food intake [66-69]. Other $\mathrm{CB}_{1} \mathrm{R}$ agonists were also reported to increase sucrose consumption [64,70] and hyperphagia [71]. An interesting observation reporting hypophagia induced by high doses of $\Delta^{9}$-THC was reported in 1975 [72]. In fact, Chopra and Chopra reported in 1939 that while a weak cannabis preparation stimulates appetite, more potent cannabis preparations usually have an opposite effect [73]. Similarly, Bouquet also noted that progressive anorexia develops with chronic use of cannabis [74]. Further 
studies conducted in animals confirmed that cannabinoid administration in high doses induces hypophagia (summarized in [75]). Data on cannabis use, caloric intake, and body mass index (BMI) establish conclusive evidence that chronic cannabis use is associated with reduced BMI and obesity rates (summarized in [76]). Interestingly, despite having a lower BMI, most cannabis users appear to have increased caloric intake. This paradox can be causatively explained by the fact that heavy cannabis use results in downregulation of $\mathrm{CB}_{1} \mathrm{R}$ [77-79], which in turn may lead to weight loss [76]. In keeping with this explanation, in recent years, many studies have examined how antagonizing $C_{1} R$ affects feeding behavior and subsequently induces weight loss in obese individuals.

\section{Targeting $\mathrm{CB}_{1} \mathrm{R}$ for Treatment of Obesity: Block Centrally or Inhibit Peripherally}

Empirical studies in various animal models indicate that pharmacological blockade of $\mathrm{CB}_{1} \mathrm{R}$ with the first-in-class synthetic $\mathrm{CB}_{1} \mathrm{R}$ inverse agonist rimonabant (SR141716A) does indeed reduce weight gain and food intake in a dose-dependent manner under both fasted and non-fasted conditions [61,80-83] as well as inhibit the motivation for palatable food $[84,85]$. These data, together with the fact that animals genetically lacking $\mathrm{CB}_{1} \mathrm{R}$ are hypophagic and lean [86], led to the idea that $\mathrm{CB}_{1} \mathrm{R}$ blockade could be considered as a therapeutic tool against obesity and metabolic syndrome. Indeed, rimonabant was proven effective not only in decreasing food intake and body weight, but also in ameliorating obesity-induced insulin and leptin resistance, improving glucose homeostasis and dyslipidemias, as well as decreasing hepatic steatosis in obese/overweight individuals with metabolic syndrome [87-93]. These clinical studies led to the approval of rimonabant by the European Medicines Agency (EMA) in 2006 as an antiobesity drug under the name of Acomplia ${ }^{\circledR}$ (Sanofi-Aventis). However, growing evidence of anxiety, depression, and suicidal ideation, which was reported in a small but significant portion of individuals treated with rimonabant [94], led to its eventual withdrawal from the market in 2009. This decision affected all the big pharmaceutical companies that were developing their own $\mathrm{CB}_{1} \mathrm{R}$ blockers, and questions were raised regarding the therapeutic relevance of this class of molecules in modulating the eCB system for treatment of metabolic syndrome [95].

Despite having only a transient inhibitory effect on feeding, rimonabant was very efficacious in reducing body weight and adiposity, suggesting that $\mathrm{CB}_{1} \mathrm{R}$ blockade not only affects $\mathrm{CNS}$-mediated energy homeostasis, but also regulates energy balance via peripheral mechanisms [96]. As mentioned before, $\mathrm{CB}_{1}$ Rs are present not only in the CNS, but also in many peripheral organs. Their expression levels in adipose tissue, liver, skeletal muscle, kidney, and pancreas are elevated under obese/diabetic conditions [97-103]. A parallel elevation in tissue and circulating eCB levels in obesity has also been vastly documented $[100,102,104-111]$. By utilizing several genetic models with a specific deletion of $\mathrm{CB}_{1} \mathrm{R}$ in liver, adipose tissue, kidney, pancreas, and skeletal muscle, studies have shown that $\mathrm{CB}_{1} \mathrm{R}$ modulates peripheral metabolic function. Interestingly, deletion of hepatic $\mathrm{CB}_{1} \mathrm{R}$ was sufficient to protect obese mice from hepatic steatosis and dyslipidemia, as well as insulin and leptin resistance [100]. A specific deletion of $\mathrm{CB}_{1} \mathrm{R}$ in adipocytes resulted in complete protection from diet-induced obesity in mice [112]. Beta cell-specific $\mathrm{CB}_{1} \mathrm{R}$-knockout mice are protected from high-fat/high-sugar diet-induced pancreatic dysfunction and inflammation [113], and its specific ablation from skeletal muscle protects mice from diet- and age-induced insulin resistance [114]. Recently, we have shown that diabesity-induced renal abnormalities are mediated via $C_{1} R$ specifically located on the renal proximal tubule cells (RPTCs) $[102,115,116]$. Whereas obese or diabetic mice lacking $\mathrm{CB}_{1} \mathrm{R}$ in the RPTCs gain weight and show metabolic impairment similar to their wild-type control animals, they remain completely protected from diabesity-induced renal dysfunction, inflammation, fibrosis, lipotoxicity, and mitochondrial function $[102,115,116]$. Taken together, the apparent increase in peripheral eCB 'tone' in obesity and the key role $\mathrm{CB}_{1} \mathrm{R}$ plays in cellular/metabolic regulation in many peripheral organs suggest that targeting $C_{1} R$ in peripheral organs by limiting brain access of $C_{1} R$ blockers may improve their therapeutic efficacy via reducing their potential to cause CNS-mediated adverse effects. This idea was tested experimentally in numerous studies describing the contribution of 
the peripheral $\mathrm{eCB} / \mathrm{CB}_{1} \mathrm{R}$ system to the development of obesity and its metabolic comorbidities, as well as the therapeutic potential of peripherally restricted $C_{1} R$ antagonists to treat obesity and its sequelae.

\section{Current View Regarding Novel Peripherally Restricted $C B_{1} R$ Blockers}

Identifying novel and robust peripherally restricted $\mathrm{CB}_{1} \mathrm{R}$ antagonists devoid of brain penetration and CNS activity can be achieved by using two main paradigms: First, chemical modification of brain-penetrating $\mathrm{CB}_{1} \mathrm{R}$ blockers, such as rimonabant or other rimonabant-like compounds (such as taranabant, otenabant, ibipinabant, etc.); second, usage of computational or in vitro chemical tools to design and synthesize compounds that do not penetrate the blood-brain barrier (BBB), based on studies that characterize those properties responsible for brain penetration [117]. In both models, one should take into consideration the physicochemical properties (e.g., lipophilicity, hydrogen bonding capacity, molecular weight, and polar surface area) required for brain restriction, as well as the usage of efflux transporters, which may also depend on the compound's structure. The preferred conditions for peripherally restricting $\mathrm{CB}_{1} \mathrm{R}$ blockers are well-described elsewhere [118]. In brief, such a compound needs to be less hydrophobic and more polar in nature to make it impenetrable into the CNS, two properties that mainly govern passive diffusion of a molecule through the BBB [119,120]. To date, various novel molecules with peripheral selectivity toward $C_{1} R$ and limited $B B B$ penetration have been designed and patented by different groups (summarized in [121]; Table 1). Only those that have been characterized and tested experimentally against obesity are highlighted in the following paragraphs.

AM6545 was the first to undergo a detailed pharmacological, metabolic, and behavioral assessment in murine models of obesity. This molecule ameliorates hepatic steatosis, increases insulin sensitivity, and improves dyslipidemia in diet- and genetically induced obese mice [122]. In addition, AM6545 has been shown to reduce food intake, the meal size, the rate of feeding, and body weight in obese animals [123-125]; attenuate obesity-induced dyslipidemia via activating brown adipose tissue [126]; and reverse monosodium glutamate-induced hypometabolic and hypothalamic obesity in mice [127]. Soon after, another well-characterized novel peripherally restricted $\mathrm{CB}_{1} \mathrm{R}$ antagonist, JD5037, was developed and preclinically tested against obesity. JD5037 was found to be equally efficacious in reducing body weight and food intake, improving glycemic control, and attenuating hepatic steatosis with its brain-penetrating parent compound SLV319 (Ibipinabant ${ }^{\circledR}$ ) [128]. Its hypophagic role is most likely mediated via increasing hypothalamic leptin sensitivity, although it is inactive on brain $\mathrm{CB}_{1}$ Rs $[128,129]$. More recently, JD5037 was found to reduce hyperphagia and weight gain in Magel2 null mice, a well-established model of Prader-Willi syndrome [109], as well as to reverse fatty acid flux-, $\mathrm{CB}_{1} \mathrm{R}-$, and type I diabetes-induced renal impairment [102,116].

$A$ few other novel molecules that mostly target $C_{1} R$ in the periphery have also been synthesized and characterized, although not to the same extent as AM6545 and JD5037. Among these, TM38837, also recently termed BPR0912, has a negligible impact on brain $\mathrm{CB}_{1} \mathrm{R}$ when tested in mice, primates, and healthy individuals [130-132], and has been shown to decrease body weight in rodents [133,134] and improve the cardiometabolic complications associated with obesity via increasing thermogenesis in white and brown adipose tissues [135]. NESSO6SM, a peripherally selective $\mathrm{CB}_{1} \mathrm{R}$ neutral antagonist whose structure is related to rimonabant, was found to be efficacious in ameliorating diet- and olanzapine-induced obesity and its metabolic abnormalities [136,137]. LH-21, initially considered as a neutral peripherally restricted $C_{1} R$ blocker able to reduce food intake and body weight in rats [138-140], was recently found to penetrate the $B B B$ and reduce food intake in $\mathrm{CB}_{1} \mathrm{R}$ null mice [141]. URB447 lowers food intake and body weight in mice [142], probably via reducing fat ingestion through the gut $[143,144]$ in a $\mathrm{CB}_{1} \mathrm{R}$-dependent manner. With an $\mathrm{IC}_{50}$ value of $159 \mathrm{nM}$, Compound 1 , described by Son and colleagues in 2010, was found to be less brain-penetrating and efficacious than rimonabant in ameliorating food intake and obesity in mice [145]. With a considerably lower exposure in the brain, Compound D4, developed by 7TM Pharma, induced pronounced weight reduction in a dose-dependent manner in obese mice in comparison with rimonabant [146]. Although designed to be a P-glycoprotein (P-gp) substrate in order to decrease its brain penetration, Compound 6a, developed 
by Janssen Research \& Development, accumulated in the brain following chronic administration, suggesting that its in vivo metabolic efficacy cannot exclude blocking central $\mathrm{CB}_{1}$ Rs [147]. Compound $2 p$, which originated from the brain-penetrant $C_{1} R$ inverse agonist program of the same group, reduced glucose levels without centrally mediated behavioral effects and a reduction in food intake or body weight [148]. Lastly, TXX-522, a newly synthesized compound that exhibited minimal brain penetration while retaining high affinity and selectivity toward $\mathrm{CB}_{1} \mathrm{R}$, improved dyslipidemia, glucose homeostasis, and fat mass in obese mice without affecting their food intake [149]. Overall, $\mathrm{CB}_{1} \mathrm{Rs}$ located in the periphery can be potentially considered as clinically relevant targets for therapeutics against obesity and its comorbidities, thus warranting further preclinical development and clinical testing of the peripherally restricted $\mathrm{CB}_{1} \mathrm{R}$ blockers. Of note, in December 2017, the U.S. Food and Drug Administration (FDA) cleared the Investigational New Drug (IND) Application for JD5037 to begin Phase 1 clinical trials. However, it remains to be seen if this novel compound will clear the way for other molecules that target peripheral $\mathrm{CB}_{1}$ Rs to be fully translated into use for humans and rekindle the spark for discovering new blockbuster therapies against metabolic syndrome. 
Table 1. List of peripherally restricted cannabinoid type-1 receptor $\left(\mathrm{CB}_{1} \mathrm{R}\right)$ antagonists.

\begin{tabular}{|c|c|c|c|c|c|c|c|c|c|c|c|}
\hline Compound & $\begin{array}{c}\mathrm{CB}_{1} \mathrm{R} \\
\mathrm{Ki} / \mathrm{EC}_{50} / \mathrm{IC}_{50}\end{array}$ & $\begin{array}{c}\mathrm{CB}_{2} \mathrm{R} \\
\mathrm{Ki} / \mathrm{EC}_{50} / \mathrm{IC}_{50} \\
\end{array}$ & $\begin{array}{l}\text { Nature of } \\
\text { Compound }\end{array}$ & $\operatorname{cLog} P / \log P$ & $\begin{array}{c}\text { TPSA/PSA } \\
\left(\AA^{2}\right)\end{array}$ & HBD & $\begin{array}{c}\text { Animal } \\
\text { Model }\end{array}$ & Efficacy & $\begin{array}{l}\text { Brain/Plasma } \\
\text { Ratio }\end{array}$ & Structure & Ref. \\
\hline LH-21 & $\begin{array}{c}\mathrm{EC}_{50}=76.9 \\
\mathrm{nM}\end{array}$ & $\begin{array}{c}\mathrm{EC}_{50}=6.56 \\
\mu \mathrm{M}\end{array}$ & $\begin{array}{c}\text { Neutral } \\
\text { antagonist }\end{array}$ & N/A & $\mathrm{N} / \mathrm{A}$ & N/A & $\begin{array}{l}\text { Obese and } \\
\quad \text { lean } \\
\text { Zucker rats }\end{array}$ & $\begin{array}{l}\text { Reduces food intake, no } \\
\text { change in lipid level and } \\
\text { plasma glucose }\end{array}$ & N/A & & [138-141] \\
\hline URB447 & $\begin{array}{c}\mathrm{IC}_{50}=313 \\
\mathrm{nM}\end{array}$ & $\mathrm{IC}_{50}=41 \mathrm{nM}$ & $\begin{array}{c}\text { Neutral } \\
\text { antagonist } \\
\left(\mathrm{CB}_{1} \mathrm{R}\right) / \\
\text { agonist }\left(\mathrm{CB}_{2} \mathrm{R}\right)\end{array}$ & $\begin{array}{l}\log P= \\
6.39\end{array}$ & $\begin{array}{c}\mathrm{PSA}= \\
48.02\end{array}$ & $\mathrm{~N} / \mathrm{A}$ & $o b / o b$ mice & $\begin{array}{l}\text { Reduces food intake and } \\
\text { body weight gain }\end{array}$ & N/A & & [142-144] \\
\hline AM6545 & $\mathrm{Ki}=3.3 \mathrm{nM}$ & $\begin{array}{c}\mathrm{CB}_{1} \mathrm{R} / \mathrm{CB}_{2} \mathrm{R}> \\
100\end{array}$ & $\begin{array}{c}\text { Neutral } \\
\text { antagonist }\end{array}$ & $\log P=3.3$ & $\mathrm{PSA}=116$ & 1 & $\begin{array}{l}\mathrm{DIO} \\
\mathrm{C} 57 \mathrm{BL} / 6 \\
\text { mice }\end{array}$ & $\begin{array}{l}\text { Reduces body weight, } \\
\text { hepatic triglyceride } \\
\text { content, and } \\
\text { hepatocellular damage; } \\
\text { increases fat oxidation }\end{array}$ & 0.03 & & [122-127] \\
\hline $\begin{array}{c}\text { Compound } \\
1\end{array}$ & $\begin{array}{c}\mathrm{IC}_{50}=159 \\
\mathrm{nM}\end{array}$ & $>10 \mu \mathrm{M}$ & Antagonist & N/A & N/A & N/A & $\begin{array}{l}\mathrm{DIO} \\
\mathrm{C} 57 \mathrm{BL} / 6 \\
\text { mice }\end{array}$ & $\begin{array}{l}\text { Reduces body weight } \\
\text { and suppresses } \\
\text { DIO-induced elevation } \\
\text { in hepatic SREBP-1 } \\
\text { expression }\end{array}$ & $\begin{array}{c}\text { CLapp., } \\
\text { uptake }= \\
0.00228\end{array}$ & & [145] \\
\hline $\begin{array}{l}\text { Compound } \\
\text { D4 }\end{array}$ & $\begin{array}{c}\mathrm{IC}_{50}=2.6 \\
\mathrm{nM}\end{array}$ & $\begin{array}{c}\mathrm{CB}_{1} \mathrm{R} / \mathrm{CB}_{2} \mathrm{R}> \\
1000 \mathrm{nM}\end{array}$ & Antagonist & N/A & N/A & N/A & $\begin{array}{l}\mathrm{DIO} \\
\text { C57BL/6 } \\
\text { mice }\end{array}$ & Reduces body weight & 0.098 & & [146] \\
\hline $\begin{array}{l}\text { TM38837 } \\
\text { (BPR0912) }\end{array}$ & $\begin{array}{c}\mathrm{IC}_{50}=8.5 \\
\mathrm{nM} \\
\mathrm{EC}_{50}=18.5 \\
\mathrm{nM}\end{array}$ & $\begin{array}{c}\mathrm{IC}_{50}=605 \\
\mathrm{nM}\end{array}$ & Antagonist & $\begin{array}{l}\log P= \\
8.91\end{array}$ & $\mathrm{TPSA}=78$ & 1 & $\begin{array}{l}\text { DIO } \\
\text { C57BL/6 } \\
\text { mice }\end{array}$ & $\begin{array}{l}\text { Decreases body weight } \\
\text { and increases } \\
\text { thermogenesis }\end{array}$ & 0.03 & & [130-135] \\
\hline
\end{tabular}


Table 1. Cont.

\begin{tabular}{|c|c|c|c|c|c|c|c|c|c|c|c|}
\hline Compound & $\begin{array}{c}\mathrm{CB}_{1} \mathrm{R} \\
\mathrm{Ki} / \mathrm{EC}_{50} / \mathrm{IC}_{50}\end{array}$ & $\begin{array}{c}\mathrm{CB}_{2} \mathrm{R} \\
\mathrm{Ki} / \mathrm{EC}_{50} / \mathrm{IC}_{50} \\
\end{array}$ & $\begin{array}{l}\text { Nature of } \\
\text { Compound }\end{array}$ & $\operatorname{cLog} P / \log P$ & $\begin{array}{c}\text { TPSA/PSA } \\
\left(\AA^{2}\right)\end{array}$ & HBD & $\begin{array}{c}\text { Animal } \\
\text { Model }\end{array}$ & Efficacy & $\begin{array}{l}\text { Brain/Plasma } \\
\text { Ratio }\end{array}$ & Structure & Ref. \\
\hline JD5037 & $\mathrm{Ki}=0.35 \mathrm{nM}$ & $\begin{array}{c}\mathrm{CB}_{1} \mathrm{R} / \mathrm{CB}_{2} \mathrm{R}> \\
\quad 700 \mathrm{nM}\end{array}$ & Inverse agonist & $\operatorname{cLog} \mathrm{P}=6$ & $\mathrm{PSA}=117$ & 3 & $\begin{array}{l}\mathrm{DIO} \\
\text { C57BL/6 } \\
\text { mice }\end{array}$ & $\begin{array}{l}\text { Reduces food intake, } \\
\text { body weight, and } \\
\text { improves hormonal/ } \\
\text { metabolic abnormalities }\end{array}$ & 0.02 & & $\begin{array}{c}{[102,109,116,} \\
128,129]\end{array}$ \\
\hline $\begin{array}{l}\text { Compound } \\
14 \mathrm{~h}\end{array}$ & $\mathrm{Ki}=5.1 \mathrm{nM}$ & $\begin{array}{c}\mathrm{Ki}>10,000 \\
\mathrm{nM}\end{array}$ & Antagonist & $\log \mathrm{P}=3.7$ & N/A & N/A & $\begin{array}{l}\text { DIO } \\
\text { Sprague- } \\
\text { Dawley } \\
\text { rats }\end{array}$ & No metabolic effect & 0.13 & & [150] \\
\hline NESS06SM & $\begin{array}{c}\mathrm{Ki}=10.25 \\
\mathrm{nM}\end{array}$ & $\mathrm{Ki}>5000 \mathrm{nM}$ & $\begin{array}{c}\text { Neutral } \\
\text { antagonist }\end{array}$ & $\begin{array}{c}\operatorname{cLog} \mathrm{P}= \\
4.62\end{array}$ & $\begin{array}{c}\text { TPSA }= \\
59.39\end{array}$ & N/A & $\begin{array}{l}\text { DIO } \\
\text { C57BL/6 } \\
\text { mice }\end{array}$ & $\begin{array}{l}\text { Reduces body weight } \\
\text { and visceral fat mass, } \\
\text { improves blood glucose } \\
\text { and dyslipidemia }\end{array}$ & $\begin{array}{c}\log B B= \\
-0.038 \\
\text { (low) }\end{array}$ & & {$[136,137]$} \\
\hline $\begin{array}{c}\text { Compound } \\
2 p\end{array}$ & $\begin{array}{c}\mathrm{EC}_{50}=0.035 \\
\mu \mathrm{M}\end{array}$ & $\begin{array}{c}\mathrm{EC}_{50}=2.0 \\
\mu \mathrm{M}\end{array}$ & Inverse agonist & $\begin{array}{c}\operatorname{cLogP}= \\
7.27\end{array}$ & $\begin{array}{c}\text { TPSA }= \\
59.8\end{array}$ & N/A & $\begin{array}{l}\text { DIO } \\
\text { C57BL/6 } \\
\text { mice }\end{array}$ & $\begin{array}{l}\text { Lowers plasma glucose } \\
\text { levels }\end{array}$ & 0.05 & & [148] \\
\hline $\begin{array}{c}\text { Compound } \\
8 c\end{array}$ & $\mathrm{Ki}=8.82 \mathrm{nM}$ & $\mathrm{Ki}=1545 \mathrm{nM}$ & Inverse agonist & N/A & $\mathrm{TPSA}=76$ & N/A & N/A & N/A & 0.15 & & [151] \\
\hline TXX522 & $\begin{array}{c}\mathrm{IC}_{50}=10.33 \\
\mathrm{nmol} / \mathrm{L}\end{array}$ & $\begin{array}{c}\mathrm{IC}_{50}>10 \\
\mu \mathrm{mol} / \mathrm{L}\end{array}$ & $\begin{array}{c}\text { Neutral } \\
\text { antagonist }\end{array}$ & $\underset{7.95}{\log \mathrm{P}}=$ & $\begin{array}{c}\text { TPSA }= \\
56.73\end{array}$ & 1 & $\begin{array}{l}\mathrm{DIO} \\
\text { C57BL/6 } \\
\text { mice }\end{array}$ & $\begin{array}{l}\text { Reduces body weight } \\
\text { and fat mass, decreases } \\
\text { metabolic complications }\end{array}$ & $0.02(\mathrm{Kp})$ & & [149] \\
\hline$\underset{6 \mathbf{a}}{\text { Compound }}$ & $\begin{array}{c}\mathrm{EC}_{50}= \\
0.0082 \mu \mathrm{M}\end{array}$ & $\begin{array}{c}\mathrm{EC}_{50}>10 \\
\mu \mathrm{M}\end{array}$ & Inverse agonist & $\begin{array}{l}\operatorname{cLogP} P= \\
6.15\end{array}$ & $\begin{array}{c}\text { TPSA }= \\
86.9\end{array}$ & 2 & $\begin{array}{l}\text { DIO } \\
\text { C57BL/6 } \\
\text { mice }\end{array}$ & $\begin{array}{l}\text { Reduces body weight, } \\
\text { food intake, insulin } \\
\text { level, liver fat, and } \\
\text { cholesterol }\end{array}$ & 0.027 & & [147] \\
\hline
\end{tabular}


Table 1. Cont.

\begin{tabular}{|c|c|c|c|c|c|c|c|c|c|c|c|}
\hline Compound & $\begin{array}{c}\mathrm{CB}_{1} \mathrm{R} \\
\mathrm{Ki} / \mathrm{EC}_{50} / \mathrm{IC}_{50}\end{array}$ & $\begin{array}{c}\mathrm{CB}_{2} \mathrm{R} \\
\mathrm{Ki} / \mathrm{EC}_{50} / \mathrm{IC}_{50}\end{array}$ & $\begin{array}{l}\text { Nature of } \\
\text { Compound }\end{array}$ & $\operatorname{cLog} \mathrm{P} / \log \mathrm{P}$ & $\begin{array}{c}\text { TPSA/PSA } \\
\left(\AA^{2}\right)\end{array}$ & HBD & $\begin{array}{c}\text { Animal } \\
\text { Model }\end{array}$ & Efficacy & $\begin{array}{l}\text { Brain/Plasma } \\
\text { Ratio }\end{array}$ & Structure & Ref. \\
\hline $\begin{array}{c}\text { Compound } \\
65\end{array}$ & $\mathrm{Ki}=4.0 \mathrm{nM}$ & $\begin{array}{c}\mathrm{Ki}>10,000 \\
\mathrm{nM}\end{array}$ & Inverse agonist & N/A & $\mathrm{N} / \mathrm{A}$ & N/A & $\mathrm{N} / \mathrm{A}$ & $\mathrm{N} / \mathrm{A}$ & 0.18 & & [152] \\
\hline AJ5018 & $\begin{array}{c}\mathrm{IC}_{50}=90.4 \\
\mathrm{nM}\end{array}$ & N/A & Antagonist & N/A & N/A & $\mathrm{N} / \mathrm{A}$ & $\begin{array}{c}\text { DIO } \\
\text { C57BL/6 } \\
\text { and } d b / d b \\
\text { mice }\end{array}$ & $\begin{array}{l}\text { Reduces hyperglycemia, } \\
\text { dyslipidemia, hepatic } \\
\text { steatosis, energy } \\
\text { expenditure, and insulin } \\
\text { resistance }\end{array}$ & 0.1 & & [153] \\
\hline AJ5012 & $\mathrm{N} / \mathrm{A}$ & N/A & Antagonist & $\begin{array}{c}\mathrm{A} \log \mathrm{P}= \\
5.328\end{array}$ & $\begin{array}{l}\text { PSA }= \\
84.836\end{array}$ & $\mathrm{~N} / \mathrm{A}$ & $\begin{array}{c}\text { DIO } \\
\text { C57BL/6 } \\
\text { and } d b / d b \\
\text { mice }\end{array}$ & $\begin{array}{c}\text { Reduces weight, } \\
\text { increases energy } \\
\text { expenditure; improves } \\
\text { metabolic abnormalities, } \\
\text { glycemic control, and } \\
\text { insulin sensitivity }\end{array}$ & 0.2 & & [154] \\
\hline $\begin{array}{c}\text { Compound } \\
17 a\end{array}$ & $\mathrm{Ki}=47.1 \mathrm{nM}$ & $\begin{array}{c}\mathrm{Ki}=20,000 \\
\mathrm{nM}\end{array}$ & Antagonist & N/A & TPSA = 79 & & $\begin{array}{l}\text { Sprague } \\
\text { Dawley } \\
\text { rats }\end{array}$ & N/A & 0.0320 & & [155] \\
\hline $\begin{array}{c}\text { Compound } \\
18 a\end{array}$ & $\mathrm{Ki}=2.9 \mathrm{nM}$ & $\mathrm{Ki}=2510 \mathrm{nM}$ & Antagonist & $\mathrm{N} / \mathrm{A}$ & TPSA = 76 & & $\begin{array}{c}\text { Sprague } \\
\text { Dawley } \\
\text { rats }\end{array}$ & $\mathrm{N} / \mathrm{A}$ & 0.0214 & & [155] \\
\hline
\end{tabular}


Table 1. Cont.

\begin{tabular}{|c|c|c|c|c|c|c|c|c|c|c|c|}
\hline Compound & $\begin{array}{c}\mathrm{CB}_{1} \mathrm{R} \\
\mathrm{Ki} / \mathrm{EC}_{50} / \mathrm{IC}_{50}\end{array}$ & $\begin{array}{c}\mathrm{CB}_{2} \mathrm{R} \\
\mathrm{Ki} / \mathrm{EC}_{50} / \mathrm{IC}_{50}\end{array}$ & $\begin{array}{l}\text { Nature of } \\
\text { Compound }\end{array}$ & $c \log P / \log P$ & $\begin{array}{c}\text { TPSA/PSA } \\
\left(\AA^{2}\right)\end{array}$ & HBD & $\begin{array}{c}\text { Animal } \\
\text { Model }\end{array}$ & Efficacy & $\begin{array}{l}\text { Brain/Plasma } \\
\text { Ratio }\end{array}$ & Structure & Ref. \\
\hline $\begin{array}{c}\text { Compound } \\
18 f\end{array}$ & $\mathrm{Ki}=14.7 \mathrm{nM}$ & $\mathrm{Ki}=3349 \mathrm{nM}$ & Antagonist & N/A & TPSA = 79 & & $\begin{array}{l}\text { Sprague } \\
\text { Dawley } \\
\text { rats }\end{array}$ & $\mathrm{N} / \mathrm{A}$ & 0.379 & & [155] \\
\hline ENV-2 & $\mathrm{N} / \mathrm{A}$ & N/A & Antagonist & N/A & $\mathrm{N} / \mathrm{A}$ & N/A & Wistar rats & $\begin{array}{l}\text { Reduces glycemia and } \\
\text { dyslipidemia }\end{array}$ & N/A & & [156] \\
\hline MJ08 & $\begin{array}{c}\mathrm{Ki}=25.4 \mathrm{nM} \\
\mathrm{IC}_{50}=99.9 \\
\mathrm{nmol} / \mathrm{L}\end{array}$ & $\mathrm{N} / \mathrm{A}$ & Inverse agonist & N/A & $\mathrm{N} / \mathrm{A}$ & N/A & $\begin{array}{l}\text { Wistar rats, } \\
\text { DIO } \\
\text { C57BL/6 } \\
\text { mice }\end{array}$ & $\begin{array}{l}\text { Stimulates hepatic } \\
\text { glucose production }\end{array}$ & N/A & & {$[157,158]$} \\
\hline PISMR & $\mathrm{Ki}=57 \mathrm{nM}$ & N/A & Antagonist & N/A & $\mathrm{N} / \mathrm{A}$ & N/A & $\begin{array}{c}\mathrm{DIO} \\
\mathrm{C} 57 \mathrm{Bl} / 6 \\
\text { mice }\end{array}$ & $\begin{array}{l}\text { Reduces weight, food } \\
\text { intake, and adiposity as } \\
\text { well as improving } \\
\text { glycemic control and } \\
\text { lipid homeostasis }\end{array}$ & 0.24 & & {$[159,160]$} \\
\hline
\end{tabular}

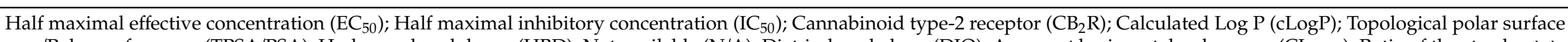
area/Polar surface area (TPSA/PSA); Hydrogen bond donor (HBD); Not available (N/A); Diet-induced obese (DIO); Apparent brain uptake clearance (CLapp); Ratio of the steady-state concentrations of the drug molecule in the brain and in the blood, expressed as $\log \left(\mathrm{C}_{\text {brain }} / \mathrm{C}_{\text {blood }} \log \mathrm{BB}\right) ;$ Brain to plasma distribution ratio $(\mathrm{Kp})$; $\mathrm{Atom}-\mathrm{based}$ Log $\mathrm{P}(\mathrm{ALog} \mathrm{P})$ 


\section{Concluding Remarks}

The appetite-stimulating 'side effect' of marijuana has been recognized for centuries. Mounting evidence supports the key role that $\mathrm{CB}_{1}$ Rs play in orexigenic signaling via central modulation of energy balance and feeding behavior. However, the influence of the $\mathrm{eCB} / \mathrm{CB}_{1} \mathrm{R}$ system on energy utilization and homeostasis cannot be solely explained by central mechanisms. Indeed, data show that this system also acts peripherally to modulate adipose tissue metabolism, kidney function, hepatic lipogenesis, muscle activity, and pancreatic homeostasis. Being tonically overactivated during obesity, the $\mathrm{eCB} / \mathrm{CB}_{1} \mathrm{R}$ system contributes to impairment in hormonal/metabolic function, propelling $\mathrm{CB}_{1} \mathrm{R}$ forward as a potential therapeutic target for obesity. Whereas the globally acting $C_{1} R$ blocker rimonabant once held tremendous promise in ameliorating the metabolic abnormalities of obesity, its CNS-mediated adverse effects limited its clinical use. Targeting the eCB system using novel compounds that block $\mathrm{CB}_{1} \mathrm{Rs}$ in periphery with negligible brain penetration still holds promise for future therapy for obesity and its sequelae.

Author Contributions: S.H. and J.T. wrote the manuscript.

Funding: This review article was made possible by the financial support provided by the ERC-2015-StG grant (\#676841) to J.T.

Conflicts of Interest: The authors declare no conflict of interest.

\section{References}

1. Pollio, A. The Name of Cannabis: A Short Guide for Nonbotanists. Cannabis Cannabinoid Res. 2016, 1, 234-238. [CrossRef]

2. McPartland, J.M. Cannabis Systematics at the Levels of Family, Genus, and Species. Cannabis Cannabinoid Res. 2018, 3, 203-212. [CrossRef] [PubMed]

3. Pacher, P.; Batkai, S.; Kunos, G. The endocannabinoid system as an emerging target of pharmacotherapy. Pharmacol. Rev. 2006, 58, 389-462. [CrossRef] [PubMed]

4. Hanus, L.O.; Meyer, S.M.; Munoz, E.; Taglialatela-Scafati, O.; Appendino, G. Phytocannabinoids: A unified critical inventory. Nat. Prod. Rep. 2016, 33, 1357-1392. [CrossRef] [PubMed]

5. Berman, P.; Futoran, K.; Lewitus, G.M.; Mukha, D.; Benami, M.; Shlomi, T.; Meiri, D. A new ESI-LC/MS approach for comprehensive metabolic profiling of phytocannabinoids in Cannabis. Sci. Rep. 2018, 8, 14280. [CrossRef]

6. Wood, T.B.; Spivey, W.T.N.; Easterfield, T.H. Cannabinol. Part I. J. Chem. Soc. 1899, 75, 20-36. [CrossRef]

7. Hanus, L.O. Pharmacological and therapeutic secrets of plant and brain (endo)cannabinoids. Med. Res. Rev. 2009, 29, 213-271. [CrossRef] [PubMed]

8. Mechoulam, R.; Shvo, Y. Hashish, I. The structure of cannabidiol. Tetrahedron 1963, 19, 2073-2078. [CrossRef]

9. Gaoni, Y.; Mechoulam, R. Isolation, structure, partial, synthesis of an active constituent of hashish. J. Am. Chem. Soc. 1964, 86, 1646-1647. [CrossRef]

10. Mechoulam, R.; Gaoni, Y. The absolute configuration of delta-1-tetrahydrocannabinol, the major active constituent of hashish. Tetrahedron Lett. 1967, 12, 1109-1111. [CrossRef]

11. Hively, R.L.; Mosher, W.A.; Hoffmann, F.W. Isolation of trans-delta-tetrahydrocannabinol from marijuana. J. Am. Chem. Soc. 1966, 88, 1832-1833. [CrossRef] [PubMed]

12. Gaoni, Y.; Mechoulam, R. The structure and synthesis of cannabigerol, a new hashish constituent. Proc. Chem. Soc. 1964,82 .

13. Gaoni, Y.; Mechoulam, R. Cannabichromene, a new active principle in hashish. Chem. Commun. 1966, 1, 20-21. [CrossRef]

14. Crombie, L.; Ponsford, R.; Shani, A.; Yagnitinsky, B.; Mechoulam, R. Hashish components. Photochemical production of cannabicyclol from cannabichromene. Tetrahedron Lett. 1968, 5771-5772. [CrossRef]

15. Devane, W.A.; Dysarz, F.A., 3rd.; Johnson, M.R.; Melvin, L.S.; Howlett, A.C. Determination and characterization of a cannabinoid receptor in rat brain. Mol. Pharmacol. 1988, 34, 605-613.

16. Matsuda, L.A.; Lolait, S.J.; Brownstein, M.J.; Young, A.C.; Bonner, T.I. Structure of a cannabinoid receptor and functional expression of the cloned cDNA. Nature 1990, 346, 561-564. [CrossRef] [PubMed] 
17. Munro, S.; Thomas, K.L.; Abu-Shaar, M. Molecular characterization of a peripheral receptor for cannabinoids. Nature 1993, 365, 61-65. [CrossRef] [PubMed]

18. Hua, T.; Vemuri, K.; Pu, M.; Qu, L.; Han, G.W.; Wu, Y.; Zhao, S.; Shui, W.; Li, S.; Korde, A.; et al. Crystal Structure of the Human Cannabinoid Receptor CB1. Cell 2016, 167, 750-762. [CrossRef] [PubMed]

19. Shao, Z.; Yin, J.; Chapman, K.; Grzemska, M.; Clark, L.; Wang, J.; Rosenbaum, D.M. High-resolution crystal structure of the human CB1 cannabinoid receptor. Nature 2016, 540, 602-606. [CrossRef] [PubMed]

20. Hua, T.; Vemuri, K.; Nikas, S.P.; Laprairie, R.B.; Wu, Y.; Qu, L.; Pu, M.; Korde, A.; Jiang, S.; Ho, J.H.; et al. Crystal structures of agonist-bound human cannabinoid receptor CB1. Nature 2017, 547, 468-471. [CrossRef] [PubMed]

21. Li, X.; Hua, T.; Vemuri, K.; Ho, J.H.; Wu, Y.; Wu, L.; Popov, P.; Benchama, O.; Zvonok, N.; Locke, K.; et al. Crystal Structure of the Human Cannabinoid Receptor CB2. Cell 2019, 176, 459-467. [CrossRef] [PubMed]

22. Howlett, A.C. Cannabinoid receptor signaling. Handb. Exp. Pharmacol. 2005, 168, 53-79.

23. Mackie, K. Distribution of cannabinoid receptors in the central and peripheral nervous system. Handb. Exp. Pharmacol. 2005, 168, 299-325.

24. Tam, J.; Hinden, L.; Drori, A.; Udi, S.; Azar, S.; Baraghithy, S. The therapeutic potential of targeting the peripheral endocannabinoid/CB1 receptor system. Eur. J. Intern. Med. 2018, 49, 23-29. [CrossRef]

25. Zou, S.; Kumar, U. Cannabinoid Receptors and the Endocannabinoid System: Signaling and Function in the Central Nervous System. Int. J. Mol. Sci. 2018, 19, 833. [CrossRef]

26. Di Marzo, V.; Piscitelli, F. The Endocannabinoid System and its Modulation by Phytocannabinoids. Neurotherapeutics 2015, 12, 692-698. [CrossRef] [PubMed]

27. Devane, W.A.; Hanus, L.; Breuer, A.; Pertwee, R.G.; Stevenson, L.A.; Griffin, G.; Gibson, D.; Mandelbaum, A.; Etinger, A.; Mechoulam, R. Isolation and structure of a brain constituent that binds to the cannabinoid receptor. Science 1992, 258, 1946-1949. [CrossRef]

28. Sugiura, T.; Kondo, S.; Sukagawa, A.; Nakane, S.; Shinoda, A.; Itoh, K.; Yamashita, A.; Waku, K. 2-Arachidonoylglycerol: A possible endogenous cannabinoid receptor ligand in brain. Biochem. Biophys. Res. Commun. 1995, 215, 89-97. [CrossRef]

29. Mechoulam, R.; Ben-Shabat, S.; Hanus, L.; Ligumsky, M.; Kaminski, N.E.; Schatz, A.R.; Gopher, A.; Almog, S.; Martin, B.R.; Compton, D.R.; et al. Identification of an endogenous 2-monoglyceride, present in canine gut, that binds to cannabinoid receptors. Biochem. Pharmacol. 1995, 50, 83-90. [CrossRef]

30. Pertwee, R.G.; Howlett, A.C.; Abood, M.E.; Alexander, S.P.; Di Marzo, V.; Elphick, M.R.; Greasley, P.J.; Hansen, H.S.; Kunos, G.; Mackie, K.; et al. International Union of Basic and Clinical Pharmacology. LXXIX. Cannabinoid receptors and their ligands: Beyond $\mathrm{CB}(1)$ and $\mathrm{CB}(2)$. Pharmacol. Rev. 2010, 62, 588-631. [CrossRef]

31. Di Marzo, V.; De Petrocellis, L. Why do cannabinoid receptors have more than one endogenous ligand? Philos. Trans. R. Soc. Lond. B Biol. Sci. 2012, 367, 3216-3228. [CrossRef] [PubMed]

32. Murataeva, N.; Straiker, A.; Mackie, K. Parsing the players: 2-arachidonoylglycerol synthesis and degradation in the CNS. Br. J. Pharmacol. 2014, 171, 1379-1391. [CrossRef] [PubMed]

33. McKinney, M.K.; Cravatt, B.F. Structure and function of fatty acid amide hydrolase. Ann. Rev. Biochem. 2005, 74, 411-432. [CrossRef] [PubMed]

34. Dinh, T.P.; Carpenter, D.; Leslie, F.M.; Freund, T.F.; Katona, I.; Sensi, S.L.; Kathuria, S.; Piomelli, D. Brain monoglyceride lipase participating in endocannabinoid inactivation. Proc. Natl. Acad. Sci. USA 2002, 99, 10819-10824. [CrossRef]

35. Di Marzo, V. 'Endocannabinoids' and other fatty acid derivatives with cannabimimetic properties: Biochemistry and possible physiopathological relevance. Biochim. Biophys. Acta 1998, 1392, 153-175. [CrossRef]

36. McPartland, J.M.; Guy, G.W.; Di Marzo, V. Care and feeding of the endocannabinoid system: A systematic review of potential clinical interventions that upregulate the endocannabinoid system. PLoS ONE 2014, 9, e89566. [CrossRef]

37. Aran, A.; Eylon, M.; Harel, M.; Polianski, L.; Nemirovski, A.; Tepper, S.; Schnapp, A.; Cassuto, H.; Wattad, N.; Tam, J. Lower circulating endocannabinoid levels in children with autism spectrum disorder. Mol. Autism 2019, 10, 2. [CrossRef] 
38. Russo, E.B. Clinical endocannabinoid deficiency (CECD): Can this concept explain therapeutic benefits of cannabis in migraine, fibromyalgia, irritable bowel syndrome and other treatment-resistant conditions? Neuro Endocrinol. Lett. 2004, 25, 31-39.

39. Niesters, M.; Overdyk, F.; Smith, T.; Aarts, L.; Dahan, A. Opioid-induced respiratory depression in paediatrics: A review of case reports. Br. J. Anaesth. 2013, 110, 175-182. [CrossRef] [PubMed]

40. Wilson, K.C.; Saukkonen, J.J. Acute respiratory failure from abused substances. J. Intensive Care Med. 2004, 19, 183-193. [CrossRef] [PubMed]

41. Kozor, R.; Grieve, S.M.; Buchholz, S.; Kaye, S.; Darke, S.; Bhindi, R.; Figtree, G.A. Regular cocaine use is associated with increased systolic blood pressure, aortic stiffness and left ventricular mass in young otherwise healthy individuals. PLoS ONE 2014, 9, e89710. [CrossRef] [PubMed]

42. May, C.N.; Ham, I.W.; Heslop, K.E.; Stone, F.A.; Mathias, C.J. Intravenous morphine causes hypertension, hyperglycaemia and increases sympatho-adrenal outflow in conscious rabbits. Clin. Sci. (Lond.) 1988, 75, 71-77. [CrossRef] [PubMed]

43. Sachs, J.; McGlade, E.; Yurgelun-Todd, D. Safety and Toxicology of Cannabinoids. Neurotherapeutics 2015, 12, 735-746. [CrossRef]

44. Adams, I.B.; Martin, B.R. Cannabis: Pharmacology and toxicology in animals and humans. Addiction 1996, 91, 1585-1614. [CrossRef]

45. Grotenhermen, F. The toxicology of cannabis and cannabis prohibition. Chem. Biodivers. 2007, 4, 1744-1769. [CrossRef] [PubMed]

46. Reece, A.S. Chronic toxicology of cannabis. Clin. Toxicol. 2009, 47, 517-524. [CrossRef] [PubMed]

47. Herkenham, M.; Lynn, A.B.; Johnson, M.R.; Melvin, L.S.; de Costa, B.R.; Rice, K.C. Characterization and localization of cannabinoid receptors in rat brain: A quantitative in vitro autoradiographic study. J. Neurosci. 1991, 11, 563-583. [CrossRef]

48. Simon, V.; Cota, D. Mechanisms in Endocrinology: Endocannabinoids and metabolism: Past, present and future. Eur. J. Endocrinol. 2017, 176, R309-R324. [CrossRef]

49. Foltin, R.W.; Brady, J.V.; Fischman, M.W. Behavioral analysis of marijuana effects on food intake in humans. Pharmacol. Biochem. Behav. 1986, 25, 577-582. [CrossRef]

50. Hollister, L.E. Hunger and appetite after single doses of marihuana, alcohol, and dextroamphetamine. Clin. Pharmacol. Ther. 1971, 12, 44-49. [CrossRef]

51. Abel, E.L. Effects of marihuana on the solution of anagrams, memory and appetite. Nature 1971, 231, $260-261$. [CrossRef] [PubMed]

52. Di Marzo, V.; Ligresti, A.; Cristino, L. The endocannabinoid system as a link between homoeostatic and hedonic pathways involved in energy balance regulation. Int. J. Obes. (Lond.) 2009, 33 (Suppl. 2), S18-S24. [CrossRef]

53. Machado Rocha, F.C.; Stefano, S.C.; De Cassia Haiek, R.; Rosa Oliveira, L.M.; Da Silveira, D.X. Therapeutic use of Cannabis sativa on chemotherapy-induced nausea and vomiting among cancer patients: Systematic review and meta-analysis. Eur. J. Cancer Care (Engl.) 2008, 17, 431-443. [CrossRef] [PubMed]

54. Badowski, M.E.; Yanful, P.K. Dronabinol oral solution in the management of anorexia and weight loss in AIDS and cancer. Ther. Clin. Risk Manag. 2018, 14, 643-651. [CrossRef] [PubMed]

55. Plasse, T.F.; Gorter, R.W.; Krasnow, S.H.; Lane, M.; Shepard, K.V.; Wadleigh, R.G. Recent clinical experience with dronabinol. Pharmacol. Biochem. Behav. 1991, 40, 695-700. [CrossRef]

56. Struwe, M.; Kaempfer, S.H.; Geiger, C.J.; Pavia, A.T.; Plasse, T.F.; Shepard, K.V.; Ries, K.; Evans, T.G. Effect of dronabinol on nutritional status in HIV infection. Ann. Pharmacother. 1993, 27, 827-831. [CrossRef] [PubMed]

57. Beal, J.E.; Olson, R.; Laubenstein, L.; Morales, J.O.; Bellman, P.; Yangco, B.; Lefkowitz, L.; Plasse, T.F.; Shepard, K.V. Dronabinol as a treatment for anorexia associated with weight loss in patients with AIDS. J. Pain Symptom Manag. 1995, 10, 89-97. [CrossRef]

58. Andries, A.; Frystyk, J.; Flyvbjerg, A.; Stoving, R.K. Dronabinol in severe, enduring anorexia nervosa: A randomized controlled trial. Int. J. Eat. Disord. 2014, 47, 18-23. [CrossRef] [PubMed]

59. Volicer, L.; Stelly, M.; Morris, J.; McLaughlin, J.; Volicer, B.J. Effects of dronabinol on anorexia and disturbed behavior in patients with Alzheimer's disease. Int. J. Geriatr. Psychiatry 1997, 12, 913-919. [CrossRef]

60. Wilson, M.M.; Philpot, C.; Morley, J.E. Anorexia of aging in long term care: Is dronabinol an effective appetite stimulant?-A pilot study. J. Nutr. Health Aging 2007, 11, 195-198. 
61. Wiley, J.L.; Burston, J.J.; Leggett, D.C.; Alekseeva, O.O.; Razdan, R.K.; Mahadevan, A.; Martin, B.R. CB1 cannabinoid receptor-mediated modulation of food intake in mice. Br. J. Pharmacol. 2005, 145, 293-300. [CrossRef] [PubMed]

62. McLaughlin, C.L.; Baile, C.A.; Bender, P.E. Cannabinols and feeding in sheep. Psychopharmacology 1979, 64, 321-323. [CrossRef] [PubMed]

63. Vaupel, D.B.; Morton, E.C. Anorexia and hyperphagia produced by five pharmacologic classes of hallucinogens. Pharmacol. Biochem. Behav. 1982, 17, 539-545. [CrossRef]

64. Brown, J.E.; Kassouny, M.; Cross, J.K. Kinetic studies of food intake and sucrose solution preference by rats treated with low doses of delta9-tetrahydrocannabinol. Behav. Biol. 1977, 20, 104-110. [CrossRef]

65. Trojniar, W.; Wise, R.A. Facilitory effect of delta 9-tetrahydrocannabinol on hypothalamically induced feeding. Psychopharmacology 1991, 103, 172-176. [CrossRef]

66. Hao, S.; Avraham, Y.; Mechoulam, R.; Berry, E.M. Low dose anandamide affects food intake, cognitive function, neurotransmitter and corticosterone levels in diet-restricted mice. Eur. J. Pharmacol. 2000, 392, 147-156. [CrossRef]

67. Williams, C.M.; Kirkham, T.C. Observational analysis of feeding induced by Delta9-THC and anandamide. Physiol. Behav. 2002, 76, 241-250. [CrossRef]

68. Williams, C.M.; Kirkham, T.C. Anandamide induces overeating: Mediation by central cannabinoid (CB1) receptors. Psychopharmacology 1999, 143, 315-317. [CrossRef]

69. Jamshidi, N.; Taylor, D.A. Anandamide administration into the ventromedial hypothalamus stimulates appetite in rats. Br. J. Pharmacol. 2001, 134, 1151-1154. [CrossRef]

70. Gallate, J.E.; Saharov, T.; Mallet, P.E.; McGregor, I.S. Increased motivation for beer in rats following administration of a cannabinoid CB1 receptor agonist. Eur. J. Pharmacol. 1999, 370, 233-240. [CrossRef]

71. Kirkham, T.C.; Williams, C.M.; Fezza, F.; Di Marzo, V. Endocannabinoid levels in rat limbic forebrain and hypothalamus in relation to fasting, feeding and satiation: Stimulation of eating by 2-arachidonoyl glycerol. Br. J. Pharmacol. 2002, 136, 550-557. [CrossRef] [PubMed]

72. Gagnon, M.A.; Elie, R. Effects of marijuana and D-amphetamine on the appetite, food consumption and various cardio-respiratory variables in man. Union Med. Can. 1975, 104, 914-921. [PubMed]

73. Chopra, R.N.; Chopra, G.S. The Present Position of Hemp-Drug Addiction in India. Indian Med. Res. Mem. 1939, 31, 1-119. [CrossRef]

74. Bouquet, J. Cannabis. Bull. Nurc. 1951, 3, 22-45.

75. Abel, E.L. Cannabis: Effects on hunger and thirst. Behav. Biol. 1975, 15, 255-281. [CrossRef]

76. Clark, T.M.; Jones, J.M.; Hall, A.G.; Tabner, S.A.; Kmiec, R.L. Theoretical Explanation for Reduced Body Mass Index and Obesity Rates in Cannabis Users. Cannabis Cannabinoid Res. 2018, 3, 259-271. [CrossRef] [PubMed]

77. Ceccarini, J.; Kuepper, R.; Kemels, D.; van Os, J.; Henquet, C.; Van Laere, K. [18F]MK-9470 PET measurement of cannabinoid CB1 receptor availability in chronic cannabis users. Add. Biol. 2015, 20, 357-367. [CrossRef] [PubMed]

78. D'Souza, D.C.; Cortes-Briones, J.A.; Ranganathan, M.; Thurnauer, H.; Creatura, G.; Surti, T.; Planeta, B.; Neumeister, A.; Pittman, B.; Normandin, M.; et al. Rapid Changes in CB1 Receptor Availability in Cannabis Dependent Males after Abstinence from Cannabis. Biol. Psychiatry Cogn. Neurosci. Neuroimaging 2016, 1, 60-67. [CrossRef]

79. Hirvonen, J.; Goodwin, R.S.; Li, C.T.; Terry, G.E.; Zoghbi, S.S.; Morse, C.; Pike, V.W.; Volkow, N.D.; Huestis, M.A.; Innis, R.B. Reversible and regionally selective downregulation of brain cannabinoid CB1 receptors in chronic daily cannabis smokers. Mol. Psychiatry 2012, 17, 642-649. [CrossRef]

80. Colombo, G.; Agabio, R.; Diaz, G.; Lobina, C.; Reali, R.; Gessa, G.L. Appetite suppression and weight loss after the cannabinoid antagonist SR 141716. Life Sci. 1998, 63, PL113-PL117. [CrossRef]

81. Arnone, M.; Maruani, J.; Chaperon, F.; Thiebot, M.H.; Poncelet, M.; Soubrie, P.; Le Fur, G. Selective inhibition of sucrose and ethanol intake by SR 141716, an antagonist of central cannabinoid (CB1) receptors. Psychopharmacology 1997, 132, 104-106. [CrossRef] [PubMed]

82. Ravinet Trillou, C.; Arnone, M.; Delgorge, C.; Gonalons, N.; Keane, P.; Maffrand, J.P.; Soubrie, P. Anti-obesity effect of SR141716, a CB1 receptor antagonist, in diet-induced obese mice. Am. J. Physiol. Regul. Integr. Comp. Physiol. 2003, 284, R345-353. [CrossRef] [PubMed]

83. Simiand, J.; Keane, M.; Keane, P.E.; Soubrie, P. SR 141716, a CB1 cannabinoid receptor antagonist, selectively reduces sweet food intake in marmoset. Behav. Pharmacol. 1998, 9, 179-181. [PubMed] 
84. Freedland, C.S.; Poston, J.S.; Porrino, L.J. Effects of SR141716A, a central cannabinoid receptor antagonist, on food-maintained responding. Pharmacol. Biochem. Behav. 2000, 67, 265-270. [CrossRef]

85. Ward, S.J.; Dykstra, L.A. The role of CB1 receptors in sweet versus fat reinforcement: Effect of CB1 receptor deletion, CB1 receptor antagonism (SR141716A) and CB1 receptor agonism (CP-55940). Behav. Pharmacol. 2005, 16, 381-388. [CrossRef]

86. Cota, D.; Marsicano, G.; Tschop, M.; Grubler, Y.; Flachskamm, C.; Schubert, M.; Auer, D.; Yassouridis, A.; Thone-Reineke, C.; Ortmann, S.; et al. The endogenous cannabinoid system affects energy balance via central orexigenic drive and peripheral lipogenesis. J. Clin. Investig. 2003, 112, 423-431. [CrossRef]

87. Despres, J.P.; Golay, A.; Sjostrom, L.; Rimonabant in Obesity-Lipids Study Group. Effects of rimonabant on metabolic risk factors in overweight patients with dyslipidemia. N. Engl. J. Med. 2005, 353, 2121-2134. [CrossRef]

88. Pi-Sunyer, F.X.; Aronne, L.J.; Heshmati, H.M.; Devin, J.; Rosenstock, J.; RIO-North America Study Group. Effect of rimonabant, a cannabinoid-1 receptor blocker, on weight and cardiometabolic risk factors in overweight or obese patients: RIO-North America: A randomized controlled trial. JAMA 2006, 295, 761-775. [CrossRef]

89. Van Gaal, L.F.; Rissanen, A.M.; Scheen, A.J.; Ziegler, O.; Rossner, S.; Group, R.I.-E.S. Effects of the cannabinoid-1 receptor blocker rimonabant on weight reduction and cardiovascular risk factors in overweight patients: 1-year experience from the RIO-Europe study. Lancet 2005, 365, 1389-1397. [CrossRef]

90. Scheen, A.J.; Finer, N.; Hollander, P.; Jensen, M.D.; Van Gaal, L.F. Efficacy and tolerability of rimonabant in overweight or obese patients with type 2 diabetes: A randomised controlled study. Lancet 2006, 368, 1660-1672. [CrossRef]

91. Despres, J.P.; Ross, R.; Boka, G.; Almeras, N.; Lemieux, I.; ADAGIO-Lipids Investigators. Effect of rimonabant on the high-triglyceride/low-HDL-cholesterol dyslipidemia, intraabdominal adiposity, and liver fat: The ADAGIO-Lipids trial. Arterioscler. Thromb. Vasc. Biol. 2009, 29, 416-423. [CrossRef] [PubMed]

92. Rosenstock, J.; Hollander, P.; Chevalier, S.; Iranmanesh, A. SERENADE: The Study Evaluating Rimonabant Efficacy in Drug-naive Diabetic Patients: Effects of monotherapy with rimonabant, the first selective CB1 receptor antagonist, on glycemic control, body weight, and lipid profile in drug-naive type 2 diabetes. Diabetes Care 2008, 31, 2169-2176. [CrossRef] [PubMed]

93. Hollander, P.A.; Amod, A.; Litwak, L.E.; Chaudhari, U. Effect of rimonabant on glycemic control in insulin-treated type 2 diabetes: The ARPEGGIO trial. Diabetes Care 2010, 33, 605-607. [CrossRef] [PubMed]

94. Christensen, R.; Kristensen, P.K.; Bartels, E.M.; Bliddal, H.; Astrup, A. Efficacy and safety of the weight-loss drug rimonabant: A meta-analysis of randomised trials. Lancet 2007, 370, 1706-1713. [CrossRef]

95. Jones, D. End of the line for cannabinoid receptor 1 as an anti-obesity target? Nat. Rev. Drug Discov. 2008, 7, 961-962. [CrossRef] [PubMed]

96. Gomez, R.; Navarro, M.; Ferrer, B.; Trigo, J.M.; Bilbao, A.; Del Arco, I.; Cippitelli, A.; Nava, F.; Piomelli, D.; Rodriguez de Fonseca, F. A peripheral mechanism for CB1 cannabinoid receptor-dependent modulation of feeding. J. Neurosci. 2002, 22, 9612-9617. [CrossRef]

97. Bensaid, M.; Gary-Bobo, M.; Esclangon, A.; Maffrand, J.P.; Le Fur, G.; Oury-Donat, F.; Soubrie, P. The cannabinoid CB1 receptor antagonist SR141716 increases Acrp30 mRNA expression in adipose tissue of obese fa/fa rats and in cultured adipocyte cells. Mol. Pharmacol. 2003, 63, 908-914. [CrossRef]

98. Jourdan, T.; Djaouti, L.; Demizieux, L.; Gresti, J.; Verges, B.; Degrace, P. CB1 antagonism exerts specific molecular effects on visceral and subcutaneous fat and reverses liver steatosis in diet-induced obese mice. Diabetes 2010, 59, 926-934. [CrossRef] [PubMed]

99. Quarta, C.; Bellocchio, L.; Mancini, G.; Mazza, R.; Cervino, C.; Braulke, L.J.; Fekete, C.; Latorre, R.; Nanni, C.; Bucci, M.; et al. CB(1) signaling in forebrain and sympathetic neurons is a key determinant of endocannabinoid actions on energy balance. Cell Metab. 2010, 11, 273-285. [CrossRef]

100. Osei-Hyiaman, D.; Liu, J.; Zhou, L.; Godlewski, G.; Harvey-White, J.; Jeong, W.I.; Batkai, S.; Marsicano, G.; Lutz, B.; Buettner, C.; et al. Hepatic CB1 receptor is required for development of diet-induced steatosis, dyslipidemia, and insulin and leptin resistance in mice. J. Clin. Investig. 2008, 118, 3160-3169. [CrossRef]

101. Pagotto, U.; Marsicano, G.; Cota, D.; Lutz, B.; Pasquali, R. The emerging role of the endocannabinoid system in endocrine regulation and energy balance. Endocr. Rev. 2006, 27, 73-100. [CrossRef] [PubMed] 
102. Udi, S.; Hinden, L.; Earley, B.; Drori, A.; Reuveni, N.; Hadar, R.; Cinar, R.; Nemirovski, A.; Tam, J. Proximal Tubular Cannabinoid-1 Receptor Regulates Obesity-Induced CKD. J. Am. Soc. Nephrol. 2017, 28, 3518-3532. [CrossRef]

103. Jourdan, T.; Godlewski, G.; Cinar, R.; Bertola, A.; Szanda, G.; Liu, J.; Tam, J.; Han, T.; Mukhopadhyay, B.; Skarulis, M.C.; et al. Activation of the Nlrp3 inflammasome in infiltrating macrophages by endocannabinoids mediates beta cell loss in type 2 diabetes. Nat. Med. 2013, 19, 1132-1140. [CrossRef]

104. Bordicchia, M.; Battistoni, I.; Mancinelli, L.; Giannini, E.; Refi, G.; Minardi, D.; Muzzonigro, G.; Mazzucchelli, R.; Montironi, R.; Piscitelli, F.; et al. Cannabinoid CB1 receptor expression in relation to visceral adipose depots, endocannabinoid levels, microvascular damage, and the presence of the Cnr1 A3813G variant in humans. Metabolism 2010, 59, 734-741. [CrossRef]

105. Engeli, S.; Bohnke, J.; Feldpausch, M.; Gorzelniak, K.; Janke, J.; Batkai, S.; Pacher, P.; Harvey-White, J.; Luft, F.C.; Sharma, A.M.; et al. Activation of the peripheral endocannabinoid system in human obesity. Diabetes 2005, 54, 2838-2843. [CrossRef] [PubMed]

106. Bluher, M.; Engeli, S.; Kloting, N.; Berndt, J.; Fasshauer, M.; Batkai, S.; Pacher, P.; Schon, M.R.; Jordan, J.; Stumvoll, M. Dysregulation of the peripheral and adipose tissue endocannabinoid system in human abdominal obesity. Diabetes 2006, 55, 3053-3060. [CrossRef] [PubMed]

107. Di Marzo, V.; Verrijken, A.; Hakkarainen, A.; Petrosino, S.; Mertens, I.; Lundbom, N.; Piscitelli, F.; Westerbacka, J.; Soro-Paavonen, A.; Matias, I.; et al. Role of insulin as a negative regulator of plasma endocannabinoid levels in obese and nonobese subjects. Eur. J. Endocrinol. 2009, 161, 715-722. [CrossRef] [PubMed]

108. Abdulnour, J.; Yasari, S.; Rabasa-Lhoret, R.; Faraj, M.; Petrosino, S.; Piscitelli, F.; Prud' Homme, D.; Di Marzo, V. Circulating endocannabinoids in insulin sensitive vs. insulin resistant obese postmenopausal women. A MONET group study. Obesity (Silver Spring) 2014, 22, 211-216. [CrossRef] [PubMed]

109. Knani, I.; Earley, B.J.; Udi, S.; Nemirovski, A.; Hadar, R.; Gammal, A.; Cinar, R.; Hirsch, H.J.; Pollak, Y.; Gross, I.; et al. Targeting the endocannabinoid/CB1 receptor system for treating obesity in Prader-Willi syndrome. Mol. Metab. 2016, 5, 1187-1199. [CrossRef] [PubMed]

110. Azar, S.; Sherf-Dagan, S.; Nemirovski, A.; Webb, M.; Raziel, A.; Keidar, A.; Goitein, D.; Sakran, N.; Shibolet, O.; Tam, J.; et al. Circulating Endocannabinoids Are Reduced Following Bariatric Surgery and Associated with Improved Metabolic Homeostasis in Humans. Obes. Surg. 2019, 29, 268-276. [CrossRef]

111. Zelber-Sagi, S.; Azar, S.; Nemirovski, A.; Webb, M.; Halpern, Z.; Shibolet, O.; Tam, J. Serum levels of endocannabinoids are independently associated with nonalcoholic fatty liver disease. Obesity 2017, 25, 94-101. [CrossRef] [PubMed]

112. Ruiz de Azua, I.; Mancini, G.; Srivastava, R.K.; Rey, A.A.; Cardinal, P.; Tedesco, L.; Zingaretti, C.M.; Sassmann, A.; Quarta, C.; Schwitter, C.; et al. Adipocyte cannabinoid receptor CB1 regulates energy homeostasis and alternatively activated macrophages. J. Clin. Investig. 2017, 127, 4148-4162. [CrossRef]

113. Gonzalez-Mariscal, I.; Montoro, R.A.; Doyle, M.E.; Liu, Q.R.; Rouse, M.; O'Connell, J.F.; Santa-Cruz Calvo, S.; Krzysik-Walker, S.M.; Ghosh, S.; Carlson, O.D.; et al. Absence of cannabinoid 1 receptor in beta cells protects against high-fat/high-sugar diet-induced beta cell dysfunction and inflammation in murine islets. Diabetologia 2018, 61, 1470-1483. [CrossRef] [PubMed]

114. Gonzalez-Mariscal, I.; Montoro, R.A.; O'Connell, J.F.; Kim, Y.; Gonzalez-Freire, M.; Liu, Q.R.; Alfaras, I.; Carlson, O.D.; Lehrmann, E.; Zhang, Y.; et al. Muscle cannabinoid 1 receptor regulates Il-6 and myostatin expression, governing physical performance and whole-body metabolism. FASEB J. 2019. [CrossRef] [PubMed]

115. Drori, A.; Permyakova, A.; Hadar, R.; Udi, S.; Nemirovski, A.; Tam, J. Cannabinoid-1 receptor regulates mitochondrial dynamics and function in renal proximal tubular cells. Diabetes Obes. Metab. 2019, 21, 146-159. [CrossRef] [PubMed]

116. Hinden, L.; Udi, S.; Drori, A.; Gammal, A.; Nemirovski, A.; Hadar, R.; Baraghithy, S.; Permyakova, A.; Geron, M.; Cohen, M.; et al. Modulation of Renal GLUT2 by the Cannabinoid-1 Receptor: Implications for the Treatment of Diabetic Nephropathy. J. Am. Soc. Nephrol. JASN 2018, 29, 434-448. [CrossRef]

117. Wager, T.T.; Chandrasekaran, R.Y.; Hou, X.; Troutman, M.D.; Verhoest, P.R.; Villalobos, A.; Will, Y. Defining desirable central nervous system drug space through the alignment of molecular properties, in vitro ADME, and safety attributes. ACS Chem. Neurosci. 2010, 1, 420-434. [CrossRef] 
118. Chorvat, R.J. Peripherally restricted CB1 receptor blockers. Bioorganic med. Chem. Lett. 2013, 23, 4751-4760. [CrossRef]

119. Sharma, M.K.; Murumkar, P.R.; Kanhed, A.M.; Giridhar, R.; Yadav, M.R. Prospective therapeutic agents for obesity: Molecular modification approaches of centrally and peripherally acting selective cannabinoid 1 receptor antagonists. Eur. J. Med. Chem. 2014, 79, 298-339. [CrossRef] [PubMed]

120. Sharma, M.K.; Murumkar, P.R.; Giridhar, R.; Yadav, M.R. Exploring structural requirements for peripherally acting 1,5-diaryl pyrazole-containing cannabinoid 1 receptor antagonists for the treatment of obesity. Mol. Divers. 2015, 19, 871-893. [CrossRef]

121. Yadav, M.R.; Murumkar, P.R. Advances in patented CB1 receptor antagonists for obesity. Pharm. Patent Anal. 2018, 7, 169-173. [CrossRef] [PubMed]

122. Tam, J.; Vemuri, V.K.; Liu, J.; Batkai, S.; Mukhopadhyay, B.; Godlewski, G.; Osei-Hyiaman, D.; Ohnuma, S.; Ambudkar, S.V.; Pickel, J.; et al. Peripheral CB1 cannabinoid receptor blockade improves cardiometabolic risk in mouse models of obesity. J. Clin. Invest. 2010, 120, 2953-2966. [CrossRef] [PubMed]

123. Cluny, N.L.; Vemuri, V.K.; Chambers, A.P.; Limebeer, C.L.; Bedard, H.; Wood, J.T.; Lutz, B.; Zimmer, A.; Parker, L.A.; Makriyannis, A.; et al. A novel peripherally restricted cannabinoid receptor antagonist, AM6545, reduces food intake and body weight, but does not cause malaise, in rodents. Br. J. Pharmacol. 2010, 161, 629-642. [CrossRef] [PubMed]

124. Argueta, D.A.; DiPatrizio, N.V. Peripheral endocannabinoid signaling controls hyperphagia in western diet-induced obesity. Physiol. Behav. 2017, 171, 32-39. [CrossRef] [PubMed]

125. Bowles, N.P.; Karatsoreos, I.N.; Li, X.; Vemuri, V.K.; Wood, J.A.; Li, Z.; Tamashiro, K.L.; Schwartz, G.J.; Makriyannis, A.M.; Kunos, G.; et al. A peripheral endocannabinoid mechanism contributes to glucocorticoid-mediated metabolic syndrome. Proc. Natl. Acad. Sci. USA 2015, 112, 285-290. [CrossRef]

126. Boon, M.R.; Kooijman, S.; van Dam, A.D.; Pelgrom, L.R.; Berbee, J.F.; Visseren, C.A.; van Aggele, R.C.; van den Hoek, A.M.; Sips, H.C.; Lombes, M.; et al. Peripheral cannabinoid 1 receptor blockade activates brown adipose tissue and diminishes dyslipidemia and obesity. FASEB J. 2014, 28, 5361-5375. [CrossRef] [PubMed]

127. Ma, H.; Zhang, G.; Mou, C.; Fu, X.; Chen, Y. Peripheral CB1 Receptor Neutral Antagonist, AM6545, Ameliorates Hypometabolic Obesity and Improves Adipokine Secretion in Monosodium Glutamate Induced Obese Mice. Front. Pharmacol. 2018, 9, 156. [CrossRef]

128. Tam, J.; Cinar, R.; Liu, J.; Godlewski, G.; Wesley, D.; Jourdan, T.; Szanda, G.; Mukhopadhyay, B.; Chedester, L.; Liow, J.S.; et al. Peripheral cannabinoid-1 receptor inverse agonism reduces obesity by reversing leptin resistance. Cell Metab. 2012, 16, 167-179. [CrossRef] [PubMed]

129. Tam, J.; Szanda, G.; Drori, A.; Liu, Z.; Cinar, R.; Kashiwaya, Y.; Reitman, M.L.; Kunos, G. Peripheral cannabinoid-1 receptor blockade restores hypothalamic leptin signaling. Mol. Metab. 2017, 6, 1113-1125. [CrossRef] [PubMed]

130. Klumpers, L.E.; Fridberg, M.; de Kam, M.L.; Little, P.B.; Jensen, N.O.; Kleinloog, H.D.; Elling, C.E.; van Gerven, J.M. Peripheral selectivity of the novel cannabinoid receptor antagonist TM38837 in healthy subjects. Br. J. Clin. Pharmacol. 2013, 76, 846-857. [CrossRef]

131. Takano, A.; Gulyas, B.; Varnas, K.; Little, P.B.; Noerregaard, P.K.; Jensen, N.O.; Elling, C.E.; Halldin, C. Low brain CB1 receptor occupancy by a second generation CB1 receptor antagonist TM38837 in comparison with rimonabant in nonhuman primates: A PET study. Synapse 2014, 68, 89-97. [CrossRef]

132. Hung, M.S.; Chang, C.P.; Li, T.C.; Yeh, T.K.; Song, J.S.; Lin, Y.; Wu, C.H.; Kuo, P.C.; Amancha, P.K.; Wong, Y.C.; et al. Discovery of 1-(2,4-dichlorophenyl)-4-ethyl-5-(5-(2-(4-(trifluoromethyl)phenyl)ethynyl)thiophe n-2-yl)-N-(piperidin-1-yl)-1H-pyrazole-3-carboxamide as a potential peripheral cannabinoid-1 receptor inverse agonist. ChemMedChem 2010, 5, 1439-1443. [CrossRef]

133. Ward, S.J.; Raffa, R.B. Rimonabant redux and strategies to improve the future outlook of CB1 receptor neutral-antagonist/inverse-agonist therapies. Obesity 2011, 19, 1325-1334. [CrossRef] [PubMed]

134. Noerregaard, P.K.; Fridberg, M.; Elling, C.E. TM38837-A novel second generation peripheral selective CB1 receptor antagonist with efficacy and potency in rodent obesity models equal to brain-penetrant CB1 antagonist rimonabant. In Proceedings of the 20th Annual Symposium of the International Cannabinoid Research Society, Lund, Sweden, 23-27 July 2010.

135. Hsiao, W.C.; Shia, K.S.; Wang, Y.T.; Yeh, Y.N.; Chang, C.P.; Lin, Y.; Chen, P.H.; Wu, C.H.; Chao, Y.S.; Hung, M.S. A novel peripheral cannabinoid receptor 1 antagonist, BPR0912, reduces weight independently of food intake and modulates thermogenesis. Diabetes Obes. Metab. 2015, 17, 495-504. [CrossRef] 
136. Mastinu, A.; Pira, M.; Pinna, G.A.; Pisu, C.; Casu, M.A.; Reali, R.; Marcello, S.; Murineddu, G.; Lazzari, P. NESS06SM reduces body weight with an improved profile relative to SR141716A. Pharmacol. Res. 2013, 74, 94-108. [CrossRef] [PubMed]

137. Lazzari, P.; Serra, V.; Marcello, S.; Pira, M.; Mastinu, A. Metabolic side effects induced by olanzapine treatment are neutralized by CB1 receptor antagonist compounds co-administration in female rats. Eur. Neuropsychopharmacol. 2017, 27, 667-678. [CrossRef] [PubMed]

138. Pavon, F.J.; Bilbao, A.; Hernandez-Folgado, L.; Cippitelli, A.; Jagerovic, N.; Abellan, G.; Rodriguez-Franco, M.A.; Serrano, A.; Macias, M.; Gomez, R.; et al. Antiobesity effects of the novel in vivo neutral cannabinoid receptor antagonist 5-(4-chlorophenyl)-1-(2,4-dichlorophenyl)-3-hexyl-1H-1,2,4-triazole-LH 21. Neuropharmacology 2006, 51, 358-366. [CrossRef] [PubMed]

139. Pavon, F.J.; Serrano, A.; Perez-Valero, V.; Jagerovic, N.; Hernandez-Folgado, L.; Bermudez-Silva, F.J.; Macias, M.; Goya, P.; de Fonseca, F.R. Central versus peripheral antagonism of cannabinoid CB1 receptor in obesity: Effects of LH-21, a peripherally acting neutral cannabinoid receptor antagonist, in Zucker rats. J. Neuroendocrinol. 2008, 20 (Suppl. 1), 116-123. [CrossRef]

140. Alonso, M.; Serrano, A.; Vida, M.; Crespillo, A.; Hernandez-Folgado, L.; Jagerovic, N.; Goya, P.; Reyes-Cabello, C.; Perez-Valero, V.; Decara, J.; et al. Anti-obesity efficacy of LH-21, a cannabinoid CB(1) receptor antagonist with poor brain penetration, in diet-induced obese rats. Br. J. Pharmacol. 2012, 165, 2274-2291. [CrossRef]

141. Chen, R.Z.; Frassetto, A.; Lao, J.Z.; Huang, R.R.; Xiao, J.C.; Clements, M.J.; Walsh, T.F.; Hale, J.J.; Wang, J.; Tong, X.; et al. Pharmacological evaluation of LH-21, a newly discovered molecule that binds to cannabinoid CB1 receptor. Eur. J. Pharmacol. 2008, 584, 338-342. [CrossRef] [PubMed]

142. LoVerme, J.; Duranti, A.; Tontini, A.; Spadoni, G.; Mor, M.; Rivara, S.; Stella, N.; Xu, C.; Tarzia, G.; Piomelli, D. Synthesis and characterization of a peripherally restricted CB1 cannabinoid antagonist, URB447, that reduces feeding and body-weight gain in mice. Bioorganic Med. Chem. Lett. 2009, 19, 639-643. [CrossRef]

143. DiPatrizio, N.V.; Astarita, G.; Schwartz, G.; Li, X.; Piomelli, D. Endocannabinoid signal in the gut controls dietary fat intake. Proc. Natl. Acad. Sci. USA 2011, 108, 12904-12908. [CrossRef] [PubMed]

144. DiPatrizio, N.V.; Joslin, A.; Jung, K.M.; Piomelli, D. Endocannabinoid signaling in the gut mediates preference for dietary unsaturated fats. FASEB J. 2013, 27, 2513-2520. [CrossRef]

145. Son, M.H.; Kim, H.D.; Chae, Y.N.; Kim, M.K.; Shin, C.Y.; Ahn, G.J.; Choi, S.H.; Yang, E.K.; Park, K.J.; Chae, H.W.; et al. Peripherally acting CB1-receptor antagonist: The relative importance of central and peripheral CB1 receptors in adiposity control. Int. J. Obes. 2010, 34, 547-556. [CrossRef] [PubMed]

146. Receveur, J.M.; Murray, A.; Linget, J.M.; Norregaard, P.K.; Cooper, M.; Bjurling, E.; Nielsen, P.A.; Hogberg, T. Conversion of 4-cyanomethyl-pyrazole-3-carboxamides into CB1 antagonists with lowered propensity to pass the blood-brain-barrier. Bioorganic Med. Chem. Lett. 2010, 20, 453-457. [CrossRef] [PubMed]

147. Zhang, Y.M.; Greco, M.N.; Macielag, M.J.; Teleha, C.A.; DesJarlais, R.L.; Tang, Y.; Ho, G.; Hou, C.; Chen, C.; Zhao, S.; et al. 6-Benzhydryl-4-amino-quinolin-2-ones as Potent Cannabinoid Type 1 (CB1) Receptor Inverse Agonists and Chemical Modifications for Peripheral Selectivity. J. Med. Chem. 2018, 61, 10276-10298. [CrossRef]

148. Matthews, J.M.; McNally, J.J.; Connolly, P.J.; Xia, M.; Zhu, B.; Black, S.; Chen, C.; Hou, C.; Liang, Y.; Tang, Y.; et al. Tetrahydroindazole derivatives as potent and peripherally selective cannabinoid-1 (CB1) receptor inverse agonists. Bioorganic Med. Chem. Lett. 2016, 26, 5346-5349. [CrossRef]

149. Chen, W.; Shui, F.; Liu, C.; Zhou, X.; Li, W.; Zheng, Z.; Fu, W.; Wang, L. Novel Peripherally Restricted Cannabinoid 1 Receptor Selective Antagonist TXX-522 with Prominent Weight-Loss Efficacy in Diet Induced Obese Mice. Front. Pharmacol. 2017, 8, 707. [CrossRef]

150. Rover, S.; Andjelkovic, M.; Benardeau, A.; Chaput, E.; Guba, W.; Hebeisen, P.; Mohr, S.; Nettekoven, M.; Obst, U.; Richter, W.F.; et al. 6-Alkoxy-5-aryl-3-pyridinecarboxamides, a new series of bioavailable cannabinoid receptor type 1 (CB1) antagonists including peripherally selective compounds. J. Med. Chem. 2013, 56, 9874-9896. [CrossRef]

151. Fulp, A.; Zhang, Y.; Bortoff, K.; Seltzman, H.; Snyder, R.; Wiethe, R.; Amato, G.; Maitra, R. Pyrazole antagonists of the CB1 receptor with reduced brain penetration. Bioorg Med. Chem. 2016, 24, 1063-1070. [CrossRef]

152. Amato, G.S.; Manke, A.; Vasukuttan, V.; Wiethe, R.W.; Snyder, R.W.; Runyon, S.P.; Maitra, R. Synthesis and pharmacological characterization of functionalized 6-piperazin-1-yl-purines as cannabinoid receptor 1 (CB1) inverse agonists. Bioorg Med. Chem. 2018, 26, 4518-4531. [CrossRef] [PubMed] 
153. Han, J.H.; Shin, H.; Rho, J.G.; Kim, J.E.; Son, D.H.; Yoon, J.; Lee, Y.J.; Park, J.H.; Song, B.J.; Choi, C.S.; et al. Peripheral cannabinoid 1 receptor blockade mitigates adipose tissue inflammation via NLRP3 inflammasome in mouse models of obesity. Diabetes Obes. Metab 2018, 20, 2179-2189. [CrossRef]

154. Han, J.H.; Shin, H.; Park, J.Y.; Rho, J.G.; Son, D.H.; Kim, K.W.; Seong, J.K.; Yoon, S.H.; Kim, W. A novel peripheral cannabinoid 1 receptor antagonist, AJ5012, improves metabolic outcomes and suppresses adipose tissue inflammation in obese mice. FASEB J. 2019, 33, 4314-4326. [CrossRef] [PubMed]

155. Fulp, A.; Bortoff, K.; Seltzman, H.; Zhang, Y.; Mathews, J.; Snyder, R.; Fennell, T.; Maitra, R. Design and synthesis of cannabinoid receptor 1 antagonists for peripheral selectivity. J. Med. Chem. 2012, 55, 2820-2834. [CrossRef] [PubMed]

156. Hernandez-Vazquez, E.; Ocampo-Montalban, H.; Ceron-Romero, L.; Cruz, M.; Gomez-Zamudio, J.; Hiriart-Valencia, G.; Villalobos-Molina, R.; Flores-Flores, A.; Estrada-Soto, S. Antidiabetic, antidyslipidemic and toxicity profile of ENV-2: A potent pyrazole derivative against diabetes and related diseases. Eur. J. Pharmacol. 2017, 803, 159-166. [CrossRef]

157. Chen, W.; Liu, H.; Guan, H.; Xue, N.; Wang, L. Cannabinoid CB1 receptor inverse agonist MJ08 stimulates glucose production via hepatic sympathetic innervation in rats. Eur. J. Pharmacol. 2017, 814, 232-239. [CrossRef] [PubMed]

158. Chen, W.; Xu, C.; Liu, H.Y.; Long, L.; Zhang, W.; Zheng, Z.B.; Xie, Y.D.; Wang, L.L.; Li, S. Novel selective cannabinoid $\mathrm{CB}(1)$ receptor antagonist $\mathrm{MJ} 08$ with potent in vivo bioactivity and inverse agonistic effects. Acta Pharmacol. Sin. 2011, 32, 1148-1158. [CrossRef] [PubMed]

159. Seltzman, H.H.; Maitra, R.; Bortoff, K.; Henson, J.; Reggio, P.H.; Wesley, D.; Tam, J. Metabolic Profiling of CB1 Neutral Antagonists. Methods Enzymol. 2017, 593, 199-215.

160. Hurst, D.; Umejiego, U.; Lynch, D.; Seltzman, H.; Hyatt, S.; Roche, M.; McAllister, S.; Fleischer, D.; Kapur, A.; Abood, M.; et al. Biarylpyrazole inverse agonists at the cannabinoid CB1 receptor: importance of the C-3 carboxamide oxygen/lysine3.28(192) interaction. J. Med. Chem. 2006, 49, 5969-5987. [CrossRef]

(C) 2019 by the authors. Licensee MDPI, Basel, Switzerland. This article is an open access article distributed under the terms and conditions of the Creative Commons Attribution (CC BY) license (http://creativecommons.org/licenses/by/4.0/). 